This article will approach some aspects of the art visibility in Brazil during a period that spans from colony to the 1930s. We will intent to observe the sway of historical conditions of art access towards the arrangement of the Brazilian audience in the delimited period. We mean by access a physical and intellectual practice of contact with artistic production, in which art visibility associates itself to the knowledge of visual codes in the learning process of spectatorship. We will comment the connection between audience and spaces of art visibility, the challenges represented by the new codes introduced by French Mission artists, the public exhibitions and configuration of larger audiences, and $X X$ th century changes to art reception.

Keywords: Audience, visibility, visual codes. 


\section{Considerações sobre o público e o acesso às artes visuais no Brasil}

Juliana de Souza

SILVA

O artigo abordará alguns aspectos da visibilidade da arte no Brasil ao longo de um período que vai desde a colônia até a década de 1930. Pretende-se observar a influência das condições históricas do acesso à arte sobre a configuração do público brasileiro no período delimitado. Entende-se por acesso uma operação física e intelectual de contato com a produção artística, em que a visibilidade de obras de arte tem um papel tão relevante quanto o conhecimento dos códigos visuais na formação do espectador. Comentaremos a relação do público com os espaços de visibilidade da arte coIonial, os desafios representados por novos códigos visuais introduzidos pelos artistas da Missão Francesa, as exposições públicas e a formação do grande público, além das transformações do século XX para a recepção da arte.

Palavras-chave: Audiência, visibilidade, códigos visuais. 


\section{A visibilidade da arte}

Pretendemos levantar aqui algumas questões sobre as condições de acesso à arte desde a época colonial até a década de 1930. Entre elas, a visibilidade da arte e a difusão de informações sobre esse campo, questões que se referem ao acesso físico e intelectual do público à produção artística.

Guardadas as proporções, o Brasil seguiu a estrutura de fruição privada da arte desenvolvida desde o Renascimento italiano, em que a maior parte da produção artística da época era encomendada, adquirida e apreciada por uma minoria. O elitismo no Brasil também caracterizou o contato do público com a arte desde o período colonial, ligando-se a uma tradição de iconografia religiosa que, além de cumprir a finalidade institucional, também decorava o ambiente doméstico. Somente com a realização das mostras de artistas acadêmicos no século XIX, abertas ao grande público, foi possível ampliar a composição social dos espectadores de arte para além das elites econômicas e políticas.

A primeira exposição pública de arte no Brasil ocorreu somente no século XIX. Isso porque a circulação social da produção artística no período colonial se associava a uma atitude mais privativa do que pública, embora a iconografia que aqui se difundiu tivesse finalidade doutrinadora. Considerando que os consumidores de artefatos religiosos pertenciam a uma pequena parcela da sociedade, a das classes mais ricas, o destino mais comum para a encomenda de santos em talha, oratórios e retábulos móveis ${ }^{1}$, quando não as igrejas e capelas, era o espaço doméstico. Provavelmente, essa característica foi importada do colonizador português, cujo temperamento mais doméstico se refletiria no conjunto arquitetônico dos primeiros séculos de colonização ${ }^{2}$.

Até o século XIX, a maioria da população tinha, nas missas e demais cerimônias religiosas, a única oportunidade de ver os artefatos feitos por mestres reconhecidos e que possuíam meIhor acabamento. Na sociedade escravista de então, as igrejas não eram espaços públicos no sentido que conhecemos hoje, mas restringiam o acesso físico a grupos raciais específicos, como era o caso das igrejas para brancos e das exclusivas para 
negros.

Mesmo durante a segunda metade do século XVIII, quando a riqueza proveniente do ouro das Minas Gerais e dos engenhos do Nordeste patrocinou a criação do estilo barroco brasileiro e a construção e decoração de diversas edificações, o acesso da população em geral continuava ligado aos códigos visuais da tradição religiosa. O valor artístico das cidades mineiras foi somente percebido por uma geração de novos ricos educada em Portugal e na França, que defendia um modelo europeizado de sociedade para ser adotado no Brasil.

Segundo a descrição do historiador John Bury, eram homens que "não conheceram os perigos e as dificuldades vividos pelos pioneiros"; desse modo,

coube-Ihes consolidar, enriquecer e embelezar suas cidades, dando expressão plástica ao seu patriotismo (...) as novas igrejas refletiam sua inteligência versátil, sua educação acadêmica, seus gostos artísticos e a aspiração de emancipar o Brasil de Portugal (BURY, 2006, p.110).

Para essa nova geração, as artes passaram a ser vistas como um importante instrumento de refinamento da sociedade. Inspirados pelas luzes européias, os novos doutores e bacharéis participaram como patronos e público do elevado nível que a produção musical e artística, sobretudo nas Minas Gerais, atingiu na segunda metade do século XVIII.

O elitismo que caracterizou o público do período colonial permaneceu com a chegada da Missão Artística Francesa. Encarregados de irradiar "cultura e civilização" por meio da construção de edifícios públicos, da realização de festas reais e da criação da primeira academia de arte brasileira, os artistas franceses tiveram de consolidar uma cultura urbana laica para as elites locais, que, além de apegadas à religião, preferiam residir nas áreas rurais.

Na festa da aclamação de D. João VI, foram criados alguns monumentos comemorativos, tais como um templo consagrado à Minerva, um arco do triunfo e um obelisco de estilo egípcio. Elementos de uma cultura clássica e européia cujo significado era desconhecido para a maior parte da população brasileira. 
Segundo Rodrigo Naves, a profusão de emblemas e alegorias, ou seja,

A própria natureza da festa real excluía o grosso da população (...) a incompreensão, o contato com imagens e ritos desconhecidos, colocava a realeza e os nobres num patamar mais elevado, inacessível aos demais (NAVES, 1996, p.69).

A tradição clássica que formara os artistas da Missão Francesa estava arraigada a uma cultura acadêmica e humanista em exercício há mais de dois séculos no velho mundo. Não só a formação dos artistas se baseava nas fontes da Antiguidade e do Renascimento, mas também o público europeu se familiarizara com os temas e os empréstimos tomados dos grandes mestres. O problema foi tentar transpor essa tradição para uma sociedade que não tinha qualquer familiaridade (com exceção de poucos indivíduos) com as fontes clássicas (ADES et al, 1997, p.30).

Somente em 1829, três anos após o início do funcionamento da Academia Imperial de Belas Artes, ocorreu uma exposição pública de trabalhos dos professores e estudantes da Academia. Cerca de duas mil pessoas ${ }^{3}$ visitaram essa exposição, que dispôs de um pequeno catálogo com a relação de professores e alunos que expuseram pinturas históricas, projetos de arquitetura, paisagens e esculturas. No ano seguinte, foi realizada outra exposição, que se dividiu em uma mostra de arquitetura e outra somente de pintura (LUZ, 2005).

As exposições públicas tiveram edições anuais, normalmente nos meses de dezembro, e apresentaram, a partir de 1840, obras de artistas que não pertenciam à Academia, mas que tinham sido selecionadas por um júri. Chamadas de Exposições Gerais de Belas Artes, estas se tornaram eventos importantes para o cultivo das artes na cidade, estimulando artistas de várias regiões e despertando o interesse do público (LUZ, idem). Anteriormente, o interesse pelas artes visuais não alcançava nem mesmo a totalidade das elites. Como aponta o sociólogo José Carlos Durand, na segunda década do século XIX, os que possuíam pinturas e gravuras o faziam como decoração residencial, sem conhecimento para avaliar a qualidade dessas 
aquisições. Em depoimentos de viajantes estrangeiros no período, queixava-se da baixa qualidade dessas imagens, na maior parte gravuras e cópias de pinturas provenientes de lojas européias que comprovavam o pobre conhecimento em matéria de arte das elites brasileiras (DURAND, 1989, p.34-35).

Sem configurar classes homogêneas, os habitantes ricos e influentes das várias cidades brasileiras tinham interesses muito diversos, em relação aos quais a arte não tinha destaque. O discípulo de Debret, o pintor Manuel de Araújo Porto-Alegre, criticou o baixo nível cultural de seus conterrâneos brasileiros, que, segundo ele, só aspiravam por riqueza e tratavam com desleixo os assuntos artísticos do país (NAVES, op.cit., p.68).

\section{O grande público}

No ambiente cultural de meados do século XIX, os jornais e revistas abriram espaço para a crítica de arte, veiculando informações sobre as exposições dos artistas acadêmicos. A publicidade da produção artística começava a preparar um público mais heterogêneo para a freqüência das exposições. À medida que os comentários dos críticos sobre as questões técnicas, os temas escolhidos pelos pintores, e até críticas sobre a personalidade do artista constituíam a principal fonte de informação sobre as Exposições Gerais, o grande público adentrava um espaço anteriormente reservado a poucos.

As publicações Semana Ilustrada, Revista Ilustrada e Revista Brasileira difundiam as tendências estilísticas de artistas, bem como posicionamentos importantes em relação ao ensino acadêmico e a identidade da arte brasileira. Inclusive elogios à democratização do evento eram registrados, como mostra o Jornal do Commercio, em matéria publicada em 16 de dezembro de 1840: "Qualquer indivíduo desconhecido, um obreiro em oficina de escultura de madeira (...) [poderia ser aceito pelo] júri de admissão; eis os seus trabalhos expostos: vê-os o soberano, vê-os o povo.(Citado por LUZ, idem, p.62).

O prestígio das Exposições Gerais se justificava, sobretudo, pela presença do imperador Pedro II, que além da visita também concedia os prêmios e bolsas de viagem. Seu apoio à 
Academia confirmava uma percepção, baseada nos princípios iluministas, de que tal instituição permitiria o desenvolvimento da sensibilidade estética da sociedade, contribuindo para a construção de um sentido de nação.

A segunda metade do século XIX assistiu a uma mudança nos hábitos culturais das elites cariocas. A realização das exposições públicas e a importância da arte nas matérias impressas acompanhavam um maior interesse pela encomenda de pintura, sobretudo de retratos. A riqueza gerada pela economia cafeeira estimulou a vinda de muitos artistas estrangeiros para compor um aquecido mercado de retratos, importante também para os artistas nacionais. Retratos de corpo inteiro ou de busto tornaram-se o gênero preferido para consagrar os novos barões (DURAND, op.cit., p.34).

A curiosidade do grande público era estimulada pela imprensa, a qual teve um desenvolvimento significativo a partir da década de 1870. O crescimento de estabelecimentos litográficos ampliava o número de almanaques comerciais que, por sua vez, movimentava o comércio das artes. Por meio dos anúncios, a venda de oleografias (reproduções litográficas de pinturas consagradas), gravuras e estampas, na maioria das vezes editadas em Paris, era divulgada para uma sociedade interessada em decorar suas residências com arte européia. Também foram muito comuns, por volta de 1860, as litografias de moda francesas que constituíam o encarte de revistas como o Jornal das Famlias (DURAND, idem).

A litografia favorecia o consumo dos segmentos médios em razão dos preços mais modestos do que de pinturas. Além de decorar as paredes, se complementava a revistas e jornais, importantes veículos informativos para um crescente público leitor. Desse modo, inaugurava-se uma relação entre imagem e informação que se tornaria comum no século seguinte.

A exposição mais representativa da publicidade da arte durante o Segundo Império foi a Exposição Geral de 1879, importante tanto pela polêmica despertada pelos críticos, quanto pela curiosidade que se disseminou na sociedade carioca. A Academia chamava a atenção para o gosto acadêmico por meio da exposição de duas cenas de batalhas - realizadas por 
pintores consagrados que rivalizavam entre si, Vítor Meireles e Pedro Américo - e de uma mostra paralela à Exposição (que depois se tornou uma seção permanente) na Pinacoteca, chamada Coleo de Quadros Nacionais formando a Escola Brasileira. A repercussão da Exposição foi enorme e mobilizou a sociedade do Rio de Janeiro. Para um público extenso, tratava-se de um acontecimento em que caberia julgar e escolher entre os dois artistas.

A estimativa do número de visitantes à Exposição Geral de 1879 atingiu um número elevado. Segundo Ângela Luz, o registro da época informava que cerca de 270 mil pessoas teriam comparecido à exposição. Considerando que a população total registrada no censo demográfico de três anos antes era de trezentas mil pessoas, o número indicaria a presença de quase toda a população. Alegou-se, na época, que os dados teriam sido exagerados com o propósito de corroborar o sucesso da mostra. Mas, provavelmente, os visitantes tenham retornado mais de uma vez (LUZ, op.cit., p.76).

Com a proclamação da república, as Exposições Gerais receberam o nome de Salões, incorporando claramente a nomenclatura francesa. Nos Salões, eram reunidas as tendências acadêmicas e modernas (estas influenciadas pelos movimentos contemporâneos da Europa, como o realismo e o simbolismo), marcadas por uma acentuada rivalidade. Desde 1888, alguns artistas tinham abandonado a instituição, criando um ensino e uma produção paralelos. A exemplo do Ateliê Livre, montado por Rodolfo Amoedo e Rodolfo Bernardelli, entre outros artistas, que organizou exposições em duas salas do ateliê visitadas por um público expressivo. A rivalidade entre os artistas da Academia e os de fora da instituição proporcionou a curiosidade do público por mais algum tempo.

A crescente popularidade das Exposições Gerais, mais do que movida por um interesse concreto pela arte, refletia a curiosidade de uma população mobilizada pela imprensa, pelo status conferido à exposição pela presença do imperador e pela participação em uma prática cultural refinada. Como veremos adiante, a mudança de regime político não manteve o mesmo público para as exposições da Academia (então renomeada de 
Escola Nacional de Belas Artes), visto que a redução do prestígio e do atrativo produzido pelos debates na imprensa deram lugar a outras práticas de entretenimento para a população.

As Exposições Gerais representaram a primeira oportunidade de contato do grande público com as formas acadêmicas de arte. Posteriormente, a criação da Pinacoteca da Academia Imperial de Belas Artes em 1843 apresentou ao público a coleção de obras trazidas pelos artistas franceses, bem como doações e aquisições de trabalhos de alunos e professores. Embora tivesse sido organizada com o propósito de educar os estudantes da Academia, a pinacoteca também era visitada pelo público em geral, principalmente durante as Exposições Gerais. A produção acadêmica era apresentada aos visitantes como a tradição oficial, difundindo referências visuais que se consolidaram para o público em geral.

\section{0 acesso à arte no século XX}

O academicismo continuou sendo difundido, nas décadas seguintes, pelos primeiros museus de arte brasileiros. No caso de São Paulo, na primeira década do século XX, os dois museus da cidade eram freqüentados apenas por um público reduzido, composto, sobretudo, por pouquíssimos mecenas e algumas pessoas que viam as visitas como uma das poucas opções de lazer (FABRIS, 1994, p.30-31). Essa tendência elitista da freqüência de museus tinha começado na últimas décadas do século XIX, com a prática social dos salões, onde se reuniam as elites do Rio de Janeiro e São Paulo para fomentar a europeização dos costumes. Entretanto, diferentemente dos cenáculos que existiam na França desde o século XVIII, as artes visuais e a literatura não eram tão valorizados quanto a música e a dança. Isso revela que não fazia parte das preocupações dos ricos e influentes a arte como conhecimento (discussões, apreciação, crítica) como ocorrera com a elite cultural francesa, mas antes o seu uso como passatempo. Para esse fim se destinavam os estudos de pintura das moças de famílias ricas desde o fim do século anterior. 
O aumento demográfico das populações urbanas no século XX produziu um fenômeno significativo, refletido na sociedade de massa e na indústria cultural, que transformou os meios e os fins da produção artística em âmbito internacional. O interesse pelas exposições de arte foi diminuindo em comparação com o crescente interesse pelas atrações e eventos de entretenimento. No Brasil, o declínio do número de visitantes nas exposições de arte também ocorreu no início do século $X X$. Sem o incentivo e o prestígio que tiveram no Segundo Império, os Salões e as premiações sofreram uma diminuição de público considerável.

A maioria das pessoas procurava formas de lazer que se vinculassem à vida moderna. O interesse pelo entretenimento levava a população urbana brasileira a preferir as passarelas e as lojas, o cinematógrafo ou as exposições humorísticas ao espaço sério do Salão oficial ${ }^{4}$. No caso da Semana de Arte Moderna de 1922, somente o pequeno círculo que compunha a elite cultural de São Paulo esteve presente no evento. Como explica Durand, "o público que realmente se mobilizava para as exposições de artes plásticas começou a reduzir-se relativamente à população até se limitar à restrita faixa dos atuais freqüentadores de museus e galerias" (DURAND, op.cit., p.67).

A modernização das grandes cidades, principalmente do Rio de Janeiro e de São Paulo, que concentravam a vida artística e intelectual do país, era acompanhada de uma circulação social das obras de arte muito precária: poucos eram os espaços de exposição além do Salão da Escola Nacional de Belas Artes, e o mercado de arte, praticamente inexistente.

Na segunda década, os intelectuais e artistas modernistas do Rio de Janeiro que estavam insatisfeitos com a Escola Nacional de Belas Artes, promoveram novas oportunidades para o acesso à arte. Após o rompimento com a Escola, começaram a usar outros lugares para expor e discutir $\operatorname{arte}^{5}$. Desde as residências de poetas e artistas, com acesso privado para saraus e reuniões, até halls de hotéis e teatros, saguões de associações e clubes, se tornaram circuitos alternativos para exposições, conferências e declamações dos modernistas (LIMA, 2001, p.66). Também nas exposições montadas em cafés e 
bares, formava-se um público um pouco mais diversificado, incluindo transeuntes ocasionais, embora bem menos numeroso do que o se reunira nas exposições oficiais da segunda metade do século XIX.

Nesse cenário, se multiplicaram os jornais e revistas ilustradas, além de outras publicações mensais, dedicadas às artes, letras, ciências e atualidades. O grupo dos modernistas editaria importantes divulgadores de suas idéias, como as revistas Klaxon (1922), Esttica (1924) e A Revista da Antropofagia (1928), entre outras. Nas matérias da revista Paratodos, em uma espécie de coluna social, os artigos tratavam as exposições dos artistas da nova geração como um signo de distinção social. Isso fica claro com os termos empregados para caracterizar o público. Na inauguração da exposição de Cícero Dias na Políclínica, em 1928, a matéria informava que ali havia se reunido "uma chusma de gente boa", e na exposição de Tarsila Amaral no Palace Hotel, em 1929, que "Todo o Rio de Janeiro intelligente e elegante esteve lá" (LIMA, idem, p.84 e 106).

O status vinculado às artes aponta para uma característica do público brasileiro de então. Os valores plásticos modernos talvez tivessem menos importância para os visitantes, em geral, do que o fato de comparecerem à exposição. E o interesse pelas questões artísticas era exclusivo dos artistas e críticos, talvez de alguns poucos colecionadores paulistas. O que movia a maior parte dos espectadores provavelmente era a curiosida$d e^{6}$.

Um exemplo do despreparo do público brasileiro para a arte moderna foi evidenciado durante a exposição dos artistas da Escola de Paris em 1930. Organizada pelo poeta e crítico Geo-Charles e pelos irmãos Joaquim e Vicente do Rego Monteiro, a exposição percorreu três capitais: Recife, Rio de Janeiro e São Paulo. Com cerca de 90 obras de artistas europeus, entre os quais, Pablo Picasso, Georges Braque, Juan Gris e Maurice Vlaminck, a exposição representou um fracasso de público em todas as cidades.

Como explicam Moacir dos Anjos e Jorge Morais, o fracasso se justificava pela divergência entre os códigos culturais que serviam de referência às obras expostas e os que formavam 
a apreciação dos espectadores locais, notadamente de Recife. Segundo eles, o público recifense estava ligado ao tipo de arte que os movimentos artísticos modernos pretendiam superar, capacidade de decodificação estética limitada pelos valores acadêmicos e pré-modernos que, ainda àquela época, eram exaltados no campo das artes plásticas recifense (ANJOS e MORAIS, 2006). O público do Rio de Janeiro e de São Paulo, de maneira semelhante, estava mais familiarizado com os códigos acadêmicos, úteis para apreciar a produção artística européia anterior a Manet, mas inviabilizando a compreensão das inovações do século XX.

O interesse pelo moderno sairia da exclusividade do círculo intelectual e artístico a partir do fim da década de 1930, como parte da propaganda política da era Vargas. Os efeitos de uma política de urbanização e industrialização em um país predominantemente agrícola, o desejo de acompanhar a modernização do primeiro mundo, e a presença de intelectuais e artistas em instituições governamentais difundiriam a arte moderna, associando-a à cultura brasileira e sua história.

\section{Notas}

1. Não havendo autorização para outro tipo de produção em território brasileiro do que a sacra, sem escolas de arte e com as prensas proibidas, muitas das imagens de santos e profetas que circulavam na colônia eram originárias da Europa. Os modelos europeus foram de grande utilidade para os artesãos no Brasil, e com eles disputavam o comércio de talha em madeira.

2. Essa idéia é do historiador John Bury, que comparou a arquitetura das colônias portuguesa e espanhola com base em uma diferença psicológica entre os colonizadores, a qual teria promovido a exuberância das igrejas no México e a simplicidade das primeiras igrejas no Brasil. (BURY, 2006, p.107).

3.Essa quantidade equivaleria a cerca de $5 \%$ da população livre da época no Rio de Janeiro, de acordo com os dados fornecidos por Rodrigo Naves (NAVES, op.cit, p.69).

4.Em 1916, foi realizado o 1 은 Salão dos Humoristas, consagrando obras de vertente humorística de artistas como Belmiro de Almeida e o jovem Di Cavalcanti. E em 1923, o Salão da Primavera, uma espécie de salão independente, foi organizado para "superar a 'casmurrice' do meio e sanar o marasmo". (Lima, op.cit., p.73-74).

5.Em São Paulo, da mesma maneira, locais alternativos foram usados para acolher os artistas que não conseguiam expor no Liceu de Artes e Ofícios, o lugar de exposições oficial (FABRIS, 1994, p.30).

6.Anos antes, na primeira exposição de Eliseu Visconti no Brasil, montada em 1902, 0 crítico Gonzaga-Duque a considerara como uma das mais completas e importantes mostras de arte já feitas no Brasil, embora o próprio artista lamentasse não ter conseguido despertar mais que a curiosidade do público. 


\section{Referências}

ADES, Dawn et al (org.). Arte na América Latina. 1820-1980. São Paulo: Cosac \& Naify, 1997. 365p.

BURY, John. Arquitetura e Arte no Brasil colonial. Brasília: IPHAN/MONUMENTA, 2006. 256p.

CHIARELLI, Tadeu. Gonzaga-Duque: a moldura e o quadro da arte brasileira. In GONZAGA-DUQUE. A Arte Brasileira. Campinas: Mercado das Letras, 1995.270p.

DURAND, José Carlos. Arte, Privilégio e Distinção: artes plásticas, arquitetura e classe dirigente no Brasil, 1855/1985. São Paulo: Perspectiva/ EDUSP, 1989.307p.

FABRIS, Annateresa. O Futurismo Paulista: Hipóteses para o estudo da chegada da vanguarda ao Brasil. São Paulo: Perspectiva, 1994. 296p.

LUZ, Ângela A. da. Uma breve história dos Salões de Arte - da Europa ao Brasil. Rio de Janeiro: Caligrama Edições, 2005. 251 p.

NAVES, Rodrigo. A Forma Difícil. Ensaios sobre a arte brasileira. São Paulo: Ática, 1996.288p.

OLIVEIRA, Myriam A. R. de. O Aleijadinho e o Santuário de Congonhas. Roteiros do Patrimônio. Brasília: IPHAN/MONUMENTA, 2006. 134p.

BANDEIRA, Júlio. Debret e a corte no Brasil. In O Brasil Redescoberto, Rio de Janeiro: Paço Imperial/ MinC IPHAN, 1999. 130p.

LIMA, Laura de Meira. O Palace Hotel - um espaço de vanguarda no Rio de Janeiro. In CAVALCANTI, Lauro (org.). Quando o Brasil era Moderno: Artes Plásticas no Rio de Janeiro 1905-1960. Rio de Janeiro: Aeroplano, $2001.468 p$.

ANJOS, Moacir e MORAIS, Jorge V. Picasso 'visita' o Recife: a exposição da Escola de Paris em março de 1930. Scielo Brazil: Scientific Eletronic Library on line:http://www.scielo.br/scielo.php?pid=S0103$-40141998000300027 \&$ script=sci_arttext\#12not 


\section{JULIANA DE SOUZA SILVA}

Mestre em Teoria e História da Arte pelo Programa de Pós-Graduação em Artes, Instituto de Artes da Universidade de Brasilia/UnB.Licenciada em Artes Plásticas pelo Departamento de Artes Visuais, Instituto de Artes da Universidade de Brasília/ UnB. Email: jdesouzasilva@gmail.com 